\title{
ЛЮДМИЛА ПОГРЕБНЯК,
} МИКОЛА НАУМЕНКО

\section{МЕТОД АДАПТИВНОГО ПРОСТОРОВОГО КОДУВАННЯ СИГНАЛІВ ДЛЯ НЕСТАЦОНАРНИХ ЧАСТОТНО-СЕЛЕКТИВНИХ КАНАЛІВ БЕЗПРОВОДОВОГО ЗВ'ЯЗКУ}

Розглянуто сумісне застосування ортогонально-частотного мультиплексування (OFDM) та системи багатоелементних антен (MIMO) у безпроводових нестаціонарних частотноселективних каналах мереж мобільного зв'язку та мереж широкосмугового доступу. Проведено аналіз методів просторового блочного кодування (просторово-часового (STBC), просторово-частотного (SFBC), просторово-часового 3 підвищеною стійкістю до нестаціонарності (WHSTBC-CC), та просторово-частотного 3 підвищеною стійкістю до частотної селективності ( $\overline{S F})$ ) та визначено умови їх ефективного використання. Показано, що методи просторового блочного кодування є ефективними лише для окремих діапазонів значень статистичних параметрів нестаціонарності та частотної селективності (нормованого доплерівського зсуву частот та середньоквадратичної затримки поширення сигналів). Протиріччя впливу часової та частотної селективності на структурно-параметричну оптимізацію технології МIMO-OFDM об'єктивно ускладнює розробку універсального високоефективного методу просторового кодування для широкого класу нестаціонарних частотно-селективних каналів. 3 метою збільшення швидкості передачі інформації i підвищення якості обслуговування користувачів (зменшення ймовірності помилки передачі інформації) запропоновано удосконалений метод адаптивного просторового кодування сигналів. Сутність удосконалення полягає в комплексному урахуванні шумової захищеності каналу (відношення сигнал/шум), нормованого значення доплерівського зсуву частот, коефіцієнтів часової та частотної кореляції при визначені оптимального ситуативного застосування SFBC, STBC, WHSTBC-CC та $\overline{S F}$, що дозволяє забезпечити ефективне використання нестаціонарних частотно-селективних каналів 3 неінваріантними в часі параметрами. тримані наукові результати можуть бути використані при модернізації існуючих та проектуванні перспективних мереж безпроводового зв'язку.

Ключові слова: нестаціонарність, частотна-селективність, MIMO, OFDM, методи просторового кодування, мережа мобільного зв’язку, мережа широкосмугового доступу.

Вступ. В сучасному інформаційному світі спостерігається тенденція розвитку безпроводових систем зв'язку, зокрема, мереж мобільного зв'язку та широкосмугового доступу [1]. Однією з важливих задач в області безпроводових систем зв'язку є значне збільшення швидкості передачі даних і підвищення якості обслуговування користувачів (зменшення ймовірності помилки передачі інформації). Така задача особливо актуальна для мереж мобільного зв'язку та широкосмугового доступу, що функціонують в складних завадових умовах. Традиційні шляхи вирішення такої задачі (розширення частотної смуги або збільшення потужності випромінення) вичерпали себе через високу вартість частотних діапазонів і вимоги біологічного захисту. Одночасне використання технологій ортогонального частотного мультиплексування (Orthogonal Frequency Division Multiplex, OFDM) та багатоелементних антен (Multiple Input - Multiple Output, MIMO) здатне частково вирішити вказану задачу. Технологія OFDM за рахунок перетворення широкосмугового частотноселективного каналу в множину вузькосмугових підканалів з амплітудними завмираннями забезпечує відсутність міжсимвольної інтерференції, а використання багатопозиційних сигналів для модуляції кожної піднесучої OFDM - високу спектральну ефективність. В той же час, ортогональність піднесучих OFDM порушується в наслідок доплерівського зсуву частот. Застосування технології МIMO в каналах з амплітудними завмираннями дозволяє наблизити його завадостійкість до потенційної завадостійкості гаусівського каналу. 
Аналіз останніх публікацій. У роботах [1] - [5] детально розглянуто одночасне застосування ортогонального частотного мультиплексування та систем багатоелементних антен. Дослідженню методів просторового кодування присвячені роботи [2] - [4], які отримали подальший розвиток у наукових працях [5] - [8]. Аналіз робіт показав, що ефективність застосування базових методів просторового кодування (просторово-часового блочного кодування (Space-Time Block Codes, STBC) та просторово-частотного блочного кодування (Space-Frequency Block Codes, SFBC)) суттєво залежить від рівнів нестаціонарності та частотної селективності безпроводових каналів. В частотно-селективних каналах кращу завадостійкість має метод STBC, однак він є критичним до нестаціонарних змін параметрів каналу. Метод SFBC ефективний при високій нестаціонарності, проте чутливий до частотної селективності. Для підвищення стійкості методу STBC до нестаціонарності каналу доцільно використовувати алгоритм спряженої компенсації (Conjugate Cancellation, CC) з структурним удосконаленням на основі попереднього перетворення Уолша-Адамара (Walsh-Hadamard Transform, WHT) вхідних інформаційних символів кодера Аламоуті (WHSTBC-CC). Для підвищення завадостійкості методу SFBC в частотно селективних каналах використовуються методи корекції частотної характеристики в частотній та часових областях, а також удосконалений метод просторового-частотного блочного кодування $\overline{S F}$, який в залежності від об’єму ансамблю модульованих сигналів повністю або частково інваріантний до частотної селективності каналу. в залежності від об'єму ансамблю сигналів Адаптивне (комбіноване) застосування методів STBC та SFBC (ST-SF) є недостатньо ефективним в каналах з одночасно високими рівнями частотної селективності та нестаціонарності [9], [11].

Таким чином, незважаючи на високу ефективність, для окремих типів каналів, жоден 3 методів просторового кодування сигналів не може бути універсальним для забезпечення завадостійкої передачі інформації в нестаціонарних частотно-селективних каналах із неінваріантними в часі статистичними параметрами.

Тому перспективним напрямком забезпечення високошвидкісної завадостійкої передачі інформації у нестаціонарних частотно-селективних каналах $\epsilon$ удосконалення методів адаптивного просторового кодування.

Метою статті є удосконалення методу адаптивного просторового кодування (Adaptive Space Coding, ASC) сигналів на основі сумісного урахування шумової захищеності каналу, нормованого значення доплерівського зсуву частот, коефіцієнтів часової та частотної кореляції.

Виклад основного матеріалу дослідження. Проведемо аналіз методів просторового кодування сигналів в нестаціонарних частотно-селективних каналах систем безпроводового зв'язку з МIMO-OFDM.

Метод просторово-часового блочного кодування. Відповідно до методу $S T B C$ вхідна послідовність елементів ансамблю сигналів $\mathbf{d}$ [11]

$$
\{\mathbf{d}\}=\left\{d_{0}, d_{1}, \ldots, d_{N-1}, d_{N}, d_{N+1}, \ldots, d_{2 N-1}\right\},
$$

де $N$ - кількість піднесучих OFDM, представляється у вигляді двох транспонованих векторів

$$
\mathbf{d}^{(1)}=\left[d_{0} d_{1} \ldots d_{N-2} d_{N-1}\right]^{T}
$$

та

$$
\mathbf{d}^{(2)}=\left[d_{N} d_{N+1} \ldots d_{2 N-2} d_{2 N-1}\right]^{T} .
$$

Згідно з алгоритмом Аламоуті у момент часу $\mathrm{t}_{1}$ здійснюється передача векторів $\mathbf{d}^{(1)} \mathrm{i} \mathbf{d}^{(2)}$, а в момент $t_{2}$ - їх комплексно спряжених копій $\mathbf{d}^{*(1)} \mathrm{i}-\mathbf{d}^{*(2)}$.

Отримані сигнальні вектори $\mathbf{r}_{1}$ та $\mathbf{r}_{1}$ після прямого швидкого перетворення Фур'є (Fast Fourier Transform, FFT) в зазначені моменти часу $\mathrm{t}_{1}$ та $\mathrm{t}_{2}$ відповідно, описуються виразами:

$$
\mathbf{r}_{1}=\mathbf{H}^{(1)} \mathbf{d}^{(1)}+\mathbf{H}^{(2)} \mathbf{d}^{(2)}+\xi^{(1)}
$$

та

$$
\mathbf{r}_{2}=-\mathbf{H}^{(1)} \mathbf{d}^{*(2)}+\mathbf{H}^{(2)} \mathbf{d}^{*(1)}+\xi^{(2)},
$$


де $\mathbf{H}^{(i)}$ - діагональна матриця з елементами, що визначають частотну характеристику $k$-го підканалу $i$-ї антени

$$
\mathbf{H}^{(i)}=\operatorname{diag}\left[H_{0}^{(i)} H_{1}^{(i)} \ldots H_{k}^{(i)}\right], i \in \overline{1,2},
$$

$\xi^{(i)}-$ вектор значень адитивного білого гаусівського шуму

$$
\xi^{(i)}=\left[\xi_{0} \xi_{1} \ldots \xi_{N-1}\right]^{T} .
$$

У результаті додавання диференційно зважених сигналів кожного каналу (Maximal Ratio Combining, MRC) вихідні сигнали декодера STBC [12]

$$
\mathbf{z}^{(1)}=\mathbf{r}_{1} \mathbf{H}^{*(1)}+\mathbf{r}_{2}^{*} \mathbf{H}^{(2)}=\left(\overline{\mathbf{H}}^{(1)}+\overline{\mathbf{H}}^{(2)}\right) \mathbf{d}^{(1)}+\boldsymbol{\xi}^{(1)}
$$

та

$$
\mathbf{z}^{(2)}=\mathbf{r}_{1} \mathbf{H}^{*(2)}-\mathbf{r}_{2}^{*} \mathbf{H}^{(1)}=\left(\overline{\mathbf{H}}^{(1)}+\overline{\mathbf{H}}^{(2)}\right) \mathbf{d}^{(2)}+\xi^{(2)},
$$

надходять до детектора максимальної правдоподібності (Maximum Likelihood, ML), що формує оцінки переданих символів на кожній піднесучій OFDM.

Однак доплерівський зсув частот, що має місце в нестаціонарному каналі внаслідок порушення ортогональності піднесучих OFDM i виникнення міжканальної інтерференції (Interchannel Interference, ICI), знижує завадостійкість системи передачі інформації 3 використанням STBC. Результати досліджень [5], [8] свідчать, що метод просторово-часового блочного кодування достатньо ефективний за умови $f_{\partial} T \leq 0,01 . .0,03$, де $f_{\text {д }} T$ - нормоване значення доплерівського зсуву, $T$ - тривалість OFDM-символу.

Метод просторово-часового блочного кодування 3 підвищеною стійкістю до нестаціонарності. Метод $S T B C$ з підвищеною стійкістю до нестаціонарності одночасно реалізує алгоритм спряженої компенсації ICI разом із посиленим рознесенням інформаційної послідовності символів $\{\mathbf{d}\}$ шляхом їі перетворення кодером Уолша-Адамара [5], [8]:

$$
\mathbf{d}^{\left(W_{i}\right)}=\mathbf{W}_{N} \mathbf{d}^{(i)},
$$

де $\mathbf{d}^{\left(W_{i}\right)}$ - вектор вхідної послідовності символів після перетворення кодером Уолша-Адамара, $\mathbf{W}_{N}$ - одинична ортогональна матриця $N \times N$ Уолша-Адамара.

Прийняті вектори сигналів після FFT мають вигляд:

$$
\mathbf{r}_{1}^{(1)}=\mathbf{H}^{(1)} \mathbf{d}^{\left(W_{1}\right)}+\xi_{1}^{(1)}
$$

та

$$
\begin{gathered}
\mathbf{r}_{1}^{(2)}=F F T\left\{\left[h^{(2)} \otimes\left(\operatorname{IFFT}\left(\mathbf{d}^{\left(W_{2}\right)}\right)\right)^{*}\right]\right\}=\mathbf{H}^{*(2)} \mathbf{d}^{\left(W_{2}\right)}+\xi_{1}^{(2)}, \\
\mathbf{r}_{2}^{(1)}=-\mathbf{H}^{(1)} \mathbf{d}^{*\left(W_{2}\right)}+\xi_{2}^{(1)}
\end{gathered}
$$

та

$$
\mathbf{r}_{2}^{(2)}=\operatorname{FFT}\left\{\left[h^{(2)} \otimes\left(\operatorname{IFFT}\left(\mathbf{d}^{*\left(W_{1}\right)}\right)\right)^{*}\right]^{*}\right\}=\mathbf{H}^{*(2)} \mathbf{d}^{*\left(W_{1}\right)}+\boldsymbol{\xi}_{2}^{(2)},
$$

де $\mathbf{r}_{t}^{(i)}$ - вектор сигналів, що приймаються від $i$-ї антени $i \in \overline{1,2}$, в $t$-й момент часу, $t \in \overline{1,2}, \otimes-$ кругова згортка, IFFT (Inverse Fast Fourier Transform) - обернене швидке перетворення Фур' $€$.

Після оберненого перетворення Уолша-Адамара $\mathbf{W}^{-1}$ відбувається когерентне додавання сигнальних векторів:

$$
\mathbf{z}^{(1)}=\mathbf{W}_{N}^{-1}\left(\mathbf{r}_{1}^{(1)} \mathbf{H}^{*(1)}+\mathbf{r}_{2}^{*(2)} \mathbf{H}^{(2)}\right)=\left(\overline{\mathbf{H}}^{(1)}+\overline{\mathbf{H}}^{(2)}\right) \mathbf{d}^{(1)}+\boldsymbol{\eta}^{(1)}
$$

та

$$
\mathbf{z}^{(2)}=\mathbf{W}_{N}^{-1}\left(-\mathbf{r}_{2}^{*(1)} \mathbf{H}^{(1)}+\mathbf{r}_{1}^{(2)}\left(\mathbf{H}^{*(2)}\right)^{*}\right)=\left(\overline{\mathbf{H}}^{(1)}+\overline{\mathbf{H}}^{(2)}\right) \mathbf{d}^{(2)}+\boldsymbol{\eta}^{(2)},
$$

де $\boldsymbol{\eta}^{(i)}$ - вектор значень адитивного білого гаусівського шуму після оберненого перетворення Уолша-Адамара

$$
\boldsymbol{\eta}^{(i)}=\mathbf{W}^{-1} \boldsymbol{\xi}^{(i)}
$$


на основі яких детектор ML здійснює оцінку послідовності переданих інформаційних символів.

Аналіз результатів, отриманих в [8] показує, що метод WHSTBC-CC ефективний при $f_{\text {д }} T \in[0,01 ; 0,1]$. Енергетичний виграш методу WHSTBC-CC складає $5 \ldots 12$ дБ в порівнянні 3 STBC і фактично не залежить від селективності каналу.

Метод просторово-частотного блочного кодування. Згідно методу SFBC [9] вхідна інформаційна послідовність

$$
\{\mathbf{d}\}=\left\{d_{0}, d_{1}, \ldots, d_{n}, \ldots, d_{N-1}\right\},
$$

де $n-$ порядковий номер піднесучої OFDM, $n=0 . . N-1$, представляється у вигляді наступних векторів

$$
\mathbf{d}^{(1)}=\left[d_{0}-d_{1}^{*} d_{2}-d_{3}^{*} \ldots d_{N-2}-d_{N-1}^{*}\right]
$$

та

$$
\mathbf{d}^{(2)}=\left[d_{1} d_{0}^{*} d_{3} d_{2}^{*} \ldots d_{N-1} d_{N-2}^{*}\right],
$$

що одночасно передаються двома антенами протягом тривалості одного OFDM-символу.

На приймальній стороні формується сигнальний вектор

$$
\mathbf{r}=\mathbf{H}^{(1)} \mathbf{d}^{(1)}+\mathbf{H}^{(2)} \mathbf{d}^{(2)}+\boldsymbol{\xi} .
$$

Враховуючи, що $\mathbf{H}^{(i)}$ - діагональна матриця, то елементи кожного блоку $\mathbf{r}_{n}=\left[r_{n} r_{n+1}\right]$ вектору (11) мають вигляд:

$$
\begin{gathered}
r_{n}=H_{n}^{(1)} d_{n}+H_{n}^{(2)} d_{n+1}+\xi_{n}, \\
r_{n+1}=-H_{n+1}^{(1)} d_{n+1}^{*}+H_{n+1}^{(2)} d_{n}^{*}+\xi_{n+1} .
\end{gathered}
$$

В подальшому просторово-частотний декодер і детектор ML реалізують процедури аналогічні STBC.

Метод SFBC ефективний в каналах $з$ помірною селективністю ( $\Delta F_{\text {к }} \geq 2 \Delta f$, де $\Delta F_{\text {к }}$ ширина смуги когерентності каналу, $\Delta f$ - ширина смуги підканалу OFDM) та нестаціонарністю, що змінюється в діапазоні значень $f_{д} T \in[0,05,0,2]$. В каналах з високою селективністю $\left(\Delta f<\Delta F_{\text {к }}<2 \Delta f\right)$ метод SFBC потребує вдосконалення шляхом підвищення стійкості до нерівномірності амплітудно-частотної характеристики (АЧХ) каналу. Однак корекція АЧХ каналу, враховуючи нестаціонарність каналу та можливе посилення шуму, $\epsilon$ проблемною. Тому, вдосконалення SFBC доцільно здійснювати на передаючій стороні шляхом синтезу алгоритмів перетворення вихідних сигналів просторово-частотного блочного кодера, які забезпечують зниження чутливості до частотної селективності. Такий підхід реалізовано у методі просторово-частотного блочного кодування з підвищеною стійкістю до частотної селективності ( $\overline{S F}$ ) [6].

Метод просторово-частотного блочного кодування 3 підвищеною стійкістю до частотної селективності. Метод $\overline{S F}$ забезпечує перетворення частотно-селективного каналу в канал із повністю або частково кусочно-плоскою АЧХ в залежності від ансамблю сигналів, що передаються на кожній піднесучій OFDM. Він базується на реалізації властивості, сутність якої полягає в тому, що якщо певну групу піднесучих в OFDM попередньо закодувати коротким унітарним перетворенням Уолша-Адамара, елементи якого мають рівні значення, то кожна піднесуча в групі буде мати однакове миттєе відношення сигнал/шум. Виходячи 3 цього, конструктивність методу $\overline{S F}$ полягає в наступному обгрунтуванні [6].

Нехай $\mathbf{d}^{(1)}$ і $\mathbf{d}^{(2)}$ вихідні вектори (9) і (10) SFBC кодера в технології MIMO-OFDM $2 \times 1$ перед процедурою IFFT підлягають унітарному перетворенню Уолша-Адамара: 


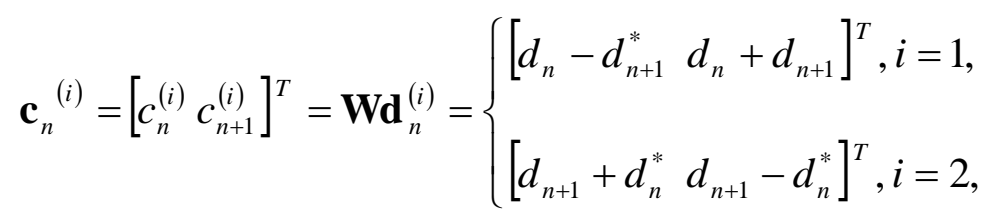

де

$$
\mathbf{W}=\frac{1}{\sqrt{2}}\left[\begin{array}{rr}
1 & 1 \\
1 & -1
\end{array}\right], \mathbf{d}_{n}^{(1)}=\left[d_{n}-d_{n+1}^{*}\right]^{T}, \mathbf{d}_{n}^{(2)}=\left[\begin{array}{ll}
d_{n+1} & d_{n}^{*}
\end{array}\right]^{T}, n=0,2, \ldots, N-2 .
$$

Тоді, будь-який елемент прийнятого сигнального вектору

$$
\mathbf{r}=\left[\begin{array}{lllll}
\mathbf{r}_{0} & \mathbf{r}_{2} & \ldots & \mathbf{r}_{n} & \ldots \\
\mathbf{r}_{N-2}
\end{array}\right]^{T}=\mathbf{H}^{(1)} \mathbf{c}^{(1)}+\mathbf{H}^{(2)} \mathbf{c}^{(2)}+\xi
$$

де

$\mathbf{H}^{(i)}=\operatorname{diag}\left[H_{0}^{(i)} H_{1}^{(i)} \ldots . H_{N-1}^{(i)}\right], \quad \mathbf{c}^{(i)}=\left[\begin{array}{lll}\mathbf{c}_{0}^{(i)} & \mathbf{c}_{1}^{(i)} \ldots \mathbf{c}_{(N / 2)-1}^{(i)}\end{array}\right]^{T}, i \in \overline{1,2}, \boldsymbol{\xi}=\left[\begin{array}{llll}\xi_{0} & \xi_{2} & \ldots & \xi_{n}\end{array} \ldots \xi_{N-2}\right]^{T}$, $\xi_{n}=\left[\xi_{n} \xi_{n+1}\right]^{T}$, що складається з пари сигналів на суміжних піднесучих OFDM:

$$
\mathbf{r}_{n}=\left[\begin{array}{ll}
r_{n} r_{n+1}
\end{array}\right]^{T}=\left[\begin{array}{ll}
H_{n}^{(1)} & 0 \\
0 & H_{n+1}^{(1)}
\end{array}\right]\left[\begin{array}{l}
c_{n}^{(1)} \\
c_{n+1}^{(1)}
\end{array}\right]+\left[\begin{array}{ll}
H_{n}^{(2)} & 0 \\
0 & H_{n+1}^{(2)}
\end{array}\right]\left[\begin{array}{l}
c_{n}^{(2)} \\
c_{n+1}^{(2)}
\end{array}\right]+\left[\begin{array}{l}
\xi_{n} \\
\xi_{n+1}
\end{array}\right],
$$

після оберненого перетворення Уолша-Адамара (Inverse Walsh-Hadamard Transform, IWHT) визначається виразом:

$$
\begin{aligned}
\mathbf{s}_{n} & =\left[\begin{array}{ll}
s_{n} & s_{n+1}
\end{array}\right]^{T}=\mathbf{W}^{-1} \mathbf{r}_{n}= \\
& =\frac{1}{2}\left[\begin{array}{cc}
H_{n}^{(1)} & H_{n+1}^{(1)} \\
H_{n}^{(1)}-H_{n+1}^{(1)}
\end{array}\right]\left[\begin{array}{l}
c_{n}^{(1)} \\
c_{n+1}^{(1)}
\end{array}\right]+\frac{1}{2}\left[\begin{array}{cc}
H_{n}^{(2)} & H_{n+1}^{(2)} \\
H_{n}^{(2)}-H_{n+1}^{(2)}
\end{array}\right]\left[\begin{array}{l}
c_{n}^{(2)} \\
c_{n+1}^{(2)}
\end{array}\right]+\left[\begin{array}{l}
\eta_{n} \\
\eta_{n+1}
\end{array}\right],
\end{aligned}
$$

який із урахуванням (12) перетворюється до наступного вигляду

$$
\begin{aligned}
\mathbf{s}_{n}= & \frac{1}{2}\left[\begin{array}{l}
\left(H_{n}^{(1)}+H_{n+1}^{(1)}\right) d_{n}-\left(H_{n}^{(1)}-H_{n+1}^{(1)}\right) d_{n+1}^{*} \\
\left(H_{n}^{(1)}-H_{n+1}^{(1)}\right) d_{n}-\left(H_{n}^{(1)}+H_{n+1}^{(1)}\right) d_{n+1}^{*}
\end{array}\right]+ \\
+ & \frac{1}{2}\left[\begin{array}{l}
\left(H_{n}^{(2)}-H_{n+1}^{(2)}\right) d_{n}^{*}+\left(H_{n}^{(2)}+H_{n+1}^{(2)}\right) d_{n+1} \\
\left(H_{n+1}^{(2)}+H_{n}^{(2)}\right) d_{n}^{*}+\left(H_{n}^{(2)}-H_{n+1}^{(2)}\right) d_{n+1}
\end{array}\right]+\left[\begin{array}{l}
\eta_{n} \\
\eta_{n+1}
\end{array}\right],
\end{aligned}
$$

де $\boldsymbol{\eta}_{n}=\left[\eta_{n} \eta_{n+1}\right]=\mathbf{W}^{-1} \boldsymbol{\xi}_{n}$.

При виконанні умови:

$$
d_{n+1}^{*}=d_{n}
$$

будь-який елемент $\mathbf{s}_{n}$ прийнятого сигнального вектору $\epsilon$ інваріантним до рівня частотної селективності каналу, тобто

$$
\mathbf{s}_{n}=\left[\begin{array}{cc}
H_{n+1}^{(1)} & 0 \\
0 & H_{n+1}^{(1)}
\end{array}\right]\left[\begin{array}{c}
d_{n} \\
-d_{n}
\end{array}\right]+\left[\begin{array}{cc}
H_{n}^{(2)} & 0 \\
0 & H_{n}^{(2)}
\end{array}\right]\left[\begin{array}{l}
d_{n}^{*} \\
d_{n}^{*}
\end{array}\right]+\left[\begin{array}{l}
\eta_{n} \\
\eta_{n+1}
\end{array}\right]=H_{n+1}^{(1)}\left[\begin{array}{ll}
d_{n}-d_{n}
\end{array}\right]^{T}+H_{n}^{(2)}\left[\begin{array}{ll}
d_{n}^{*} & d_{n}^{*}
\end{array}\right]^{T}+\eta_{n} .
$$

Очевидно, що ефективність методу $\overline{S F}$ зростає зі збільшенням кількості елементів сигнального вектору, для яких виконується умова (16), і залежить від ансамблю сигналів в MIMO-OFDM.

Аналіз структури ансамблів сигналів фазової модуляції (BPSK, Binary Phase Shift Keying), (QPSK, Quadrature Phase Shift Keying) та квадратурної амплітудної модуляції (QAM16, QAM-64, Quadrature Amplitude Modulation), що використовуються в стандартах LTE, IEEE 802.11 та 802.16 [12], дозволяє зробити наступні висновки, щодо ефективності методу $\overline{S F}$ :

а) для ансамблю сигналів з BPSK метод $\overline{S F}$ являється інваріантним до рівня частотної селективності каналу. Сигнали BPSK завжди задовольняють умові (16); 
б) для ансамблю сигналів з QАМ-М $(M>2)$ метод $\overline{S F}$ забезпечує часткову інваріантність сигналу до рівня частотної селективності каналу (в середньому для $L=\left((M / 2) / C_{M}^{2}\right) \cdot 100 \%$ пар піднесучих від їх загальної кількості). Часткова інваріантність визначається тим, що елементи вхідної послідовності d розподілені рівномірно, а перетворення Уолша-Адамара не впливає на її статистичні характеристики. Отже, для QPSK умова (16) виконується приблизно для 30 \%, а для QAM-16 - лише для 5\% піднесучих. Таким чином, метод $\overline{S F}$ є оптимальним для BPSK, але зі збільшенням обсягу ансамблю сигналів його ефективність суттєво зменшується i практично обмежена використанням ансамблю QPSK;

в) якщо умова (16) для піднесучих OFDM не виконується, тоді метод $\overline{S F}$ працює аналогічно SFBC. Дійсно, якщо $d_{n+1}^{*} \neq d_{n}$ та $H_{n}^{(1)} \approx H_{n+1}^{(1)}$ i $H_{n}^{(2)} \approx H_{n+1}^{(2)}$,

то

$$
\mathbf{s}_{n}=\frac{1}{2}\left[\begin{array}{l}
H_{n}^{(1)} d_{n}+H_{n}^{(2)} d_{n+1} \\
H_{n}^{(2)} d_{n}^{*}-H_{n}^{(1)} d_{n+1}^{*}
\end{array}\right] .
$$

В цілому доцільно відзначити, що метод $\overline{S F}$ з BPSK забезпечує практично оптимальне рознесення сигналів в каналах з високими рівнями частотної та часової селективності [6]. Він може бути ефективно використаний в низькоенергетичних каналах радіозв'язку мереж спеціального призначення, що функціонують в умовах впливу засобів радіоелектронної боротьби.

Таким чином, проведений аналіз сучасних методів просторового кодування сигналів показує їх високу ефективність для окремих типів каналів, що відрізняються різними рівнями нестаціонарності, частотної селективності та шумової захищеності. Однак, жоден із них не може бути універсальним для забезпечення необхідної завадостійкості безпроводових систем передачі в нестаціонарних частотно-селективних каналах 3 неінваріантними в часі статистичними параметрами. Об'єктивна складність розробки універсального методу просторового кодування полягає в протиріччі між впливом нестаціонарності та частотної селективності на структурно-параметричну оптимізацію технології MIMO-OFDM. Тому, для таких неінваріантних в часі каналів зі складною статистичною структурою завмирань, що представляють значний практичний інтерес, доцільно розробити метод адаптивного просторового кодування, на основі ситуативного використання кожного із розглянутих методів в залежності від результатів оцінки параметрів каналу.

Метод адаптивного просторового кодування сигналів. Аналіз ефективності методів $\mathrm{STBC}, \mathrm{SFBC}, \mathrm{WHSTBC-CC}, \overline{S F}$, а також відомі результати досліджень [11], показують, що критеріями їх оптимального використання $\epsilon$ : шумова захищеність каналу (відношення сигнал/шум) $\gamma_{\text {ш }}$, нормоване значення доплерівського зсуву $f_{\text {д }} T$, коефіцієнти часової $K_{t}$

$$
K_{t}=\frac{1}{N^{2}} \sum_{l=-N+1}^{N-1}(N-|l|) J_{0}\left[2 \pi f_{d} T\left(1+\frac{G}{N}+\frac{l}{N}\right)\right]
$$

та частотної $K_{f}$ кореляції

$$
K_{f}=\frac{(1-\lambda)\left(1-\lambda^{M} e^{-j 2 \pi M / N}\right)}{\left(1-\lambda^{M}\right)\left(1-\lambda e^{-j 2 \pi / N}\right)} \frac{1}{N^{2}} \sum_{l=-N+1}^{N-1}(N-|l|) J_{0}\left[\frac{2 \pi f_{d} T l}{N}\right]
$$

де $\lambda=e^{-T / \tau_{\max }}, G$-циклічний префікс, $N$ - кількість OFDM піднесучих, $\tau_{\max }$ - максимальне значення затримки поширення сигналу, $J_{0}[\cdot]$ - функція Бесселя нульового порядку.

Алгоритм адаптивного методу просторового кодування наведено на рис. 1 .

Вибір ансамблю сигналів здійснюється відповідно до методів адаптивної модуляції та завадостійкого кодування (Adaptive Modulation and Coding, AMC), що реалізуються практично у всіх сучасних технологіях мереж мобільного зв’язку та широкосмугового доступу. Так, 
наприклад, допустиме граничне значення сигнал/шум на вході приймача для QPSK в стандарті IEEE 802.16 специфікацій Wireless MAN-OFDM/OFDM при використані завадостійкого кодування 3 швидкостями 1/2 та 3/4 становить 9,4 та 11,2 дБ відповідно [2].

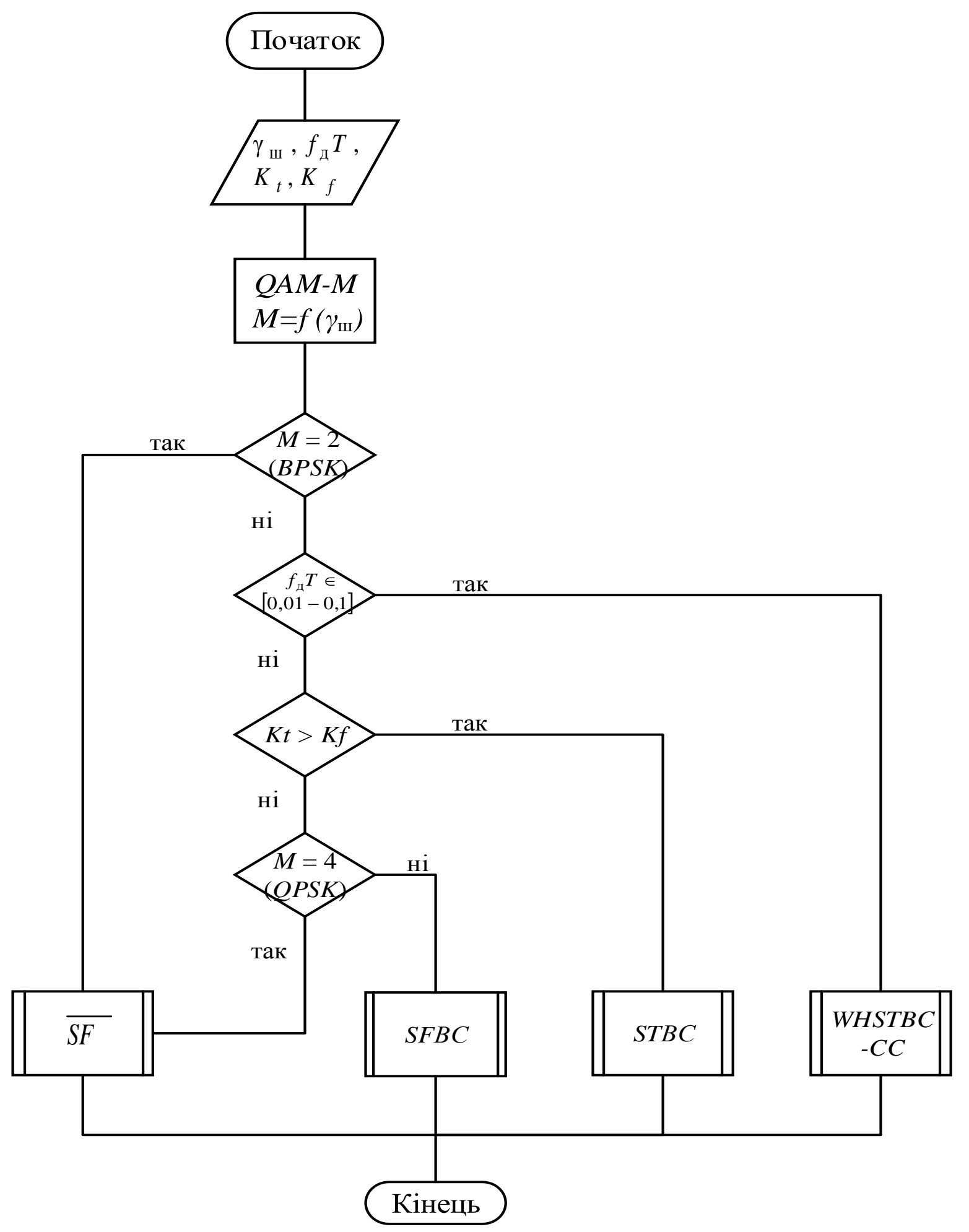

Рисунок 1 - Алгоритм адаптивного просторового кодування

Ключовим етапом алгоритму є визначення нормованих значень доплерівського зсуву частот $f_{\text {д }} T$, що належать до інтервалу $[0,01 . .0,1]$, який характеризує більшість типових безпроводових нестаціонарних каналів в яких переважає частотна селективність. Для цих каналів, відповідно до наведених вище результатів, доцільно використовувати метод WHSTBC-CC. 
При високій нестаціонарності каналу $\left(f_{\partial} T>0,1\right)$ і ансамблях сигналів, що обмежуються QPSK, пріоритетним для застосування є метод $\overline{S F}$. У разі використання ансамблю сигналів більшого обсягу його ефективність в зазначених умовах суттєво знижується, тому з метою зменшення складності реалізації доцільно використовувати метод SFBC. Аналогічно з цією ж метою в умовах помірної нестаціонарності $\left(f_{\partial} T<0,01\right)$ каналів в яких переважає частотна селективність $\left(K_{t}>K_{f}\right)$ застосовується метод STBC [11].

Результати моделювання. За допомогою імітаційного моделювання в середовищі MatLab була проведена оцінка ефективності запропонованого методу ASC у нестаціонарних частотноселективних каналах 3 інваріантними у часі параметрами ( $f_{\partial} T \in[0,01 . .0,1], \sigma \in[0,5 . .13,5]$ мс, $\gamma_{u} \in[5.20]$ дБ). В якості вихідних даних розглядалась система передачі з MIMO-OFDM $2 \times 1$, кількістю піднесучих OFDM - 64, циклічним префіксом - 16, тривалістю OFDM-символу $-2,4$ $\cdot 10^{-4}$ c, частотним інтервалом між піднесучими - 4,16 кГц, релеївським каналом 3 експоненціальним профілем затримки потужності. Завмирання в каналі згенеровано за допомогою моделі Джейкса. Вихідні параметри каналів та характеристики системи передачі $є$ актуальними для перспективних систем безпроводового зв'язку з наземними та повітряними об’єктами, що працюють в діапазоні значень несучої частоти від 0,8 до 5,9 ГГц із швидкістю руху $60 . .600$ км/год [6]. Оцінка параметрів каналу та робота системи синхронізації вважаються ідеальними.

Результати моделювання наведено на рис. 2 - 5. Аналіз графіків залежності рис. 2. Для каналів 3 помірними рівнями нестаціонарності та частотної селективності показав, що середньоквадратичне значення затримки поширення сигналу $\sigma$ та $f_{\delta} T$ змінюються 3 передачею кожного OFDM-символу за рівномірним законом розподілу в діапазонах: $\sigma \in\left[0,5 . .6,5 \cdot 10^{-6} \mathrm{c}\right]$ та $f_{\partial} T \in[0,01 . .0,1]$.

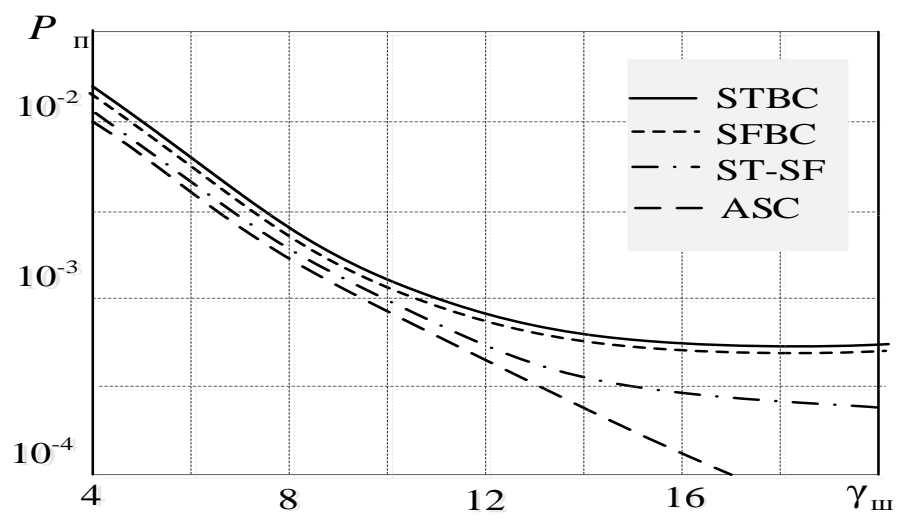

Рисунок 2 - Завадостійкість системи передачі для методів ASC, STBC, SFBC i ST-SF при

$$
f_{\text {д }} T \in[0,01 . .0,1] \text { та } \sigma \in\left[0,5 . .6,5 \cdot 10^{-6} c\right], \text { QPSK }
$$

Застосування методу ASC при $P_{\text {п }}=7 . .9 \cdot 10^{-4}$ дозволяє отримати енергетичний виграш $2,0 . .4,0$ дБ та 0,5..1,5 дБ в порівнянні з базовими STBC, SFBC та комбінованим ST-SF методами відповідно. Такий виграш $є$ результатом ефективної роботи адаптивного методу при прийомі сигналів із $f_{\text {д }} T$ та $\sigma$ близькими до верхньої межі в зазначених діапазонах дослідження i забезпечується пріоритетним використанням методу WHSTBC-CC.

На рис. 3 відображається ефективність розглянутих методів просторового кодування у каналі в якому переважає висока частотна селективність, а на рис. 4 - висока нестаціонарність.

Аналіз результатів показує, що методи STBC та SFBC в таких умовах є недостатньо ефективними $\left(P_{\text {п }}>10^{-2} \forall \gamma_{\text {ш }} \leq 12\right.$ дБ). Головною причиною цього $є$ критичність до стаціонарності слів просторового кодового блоку. 


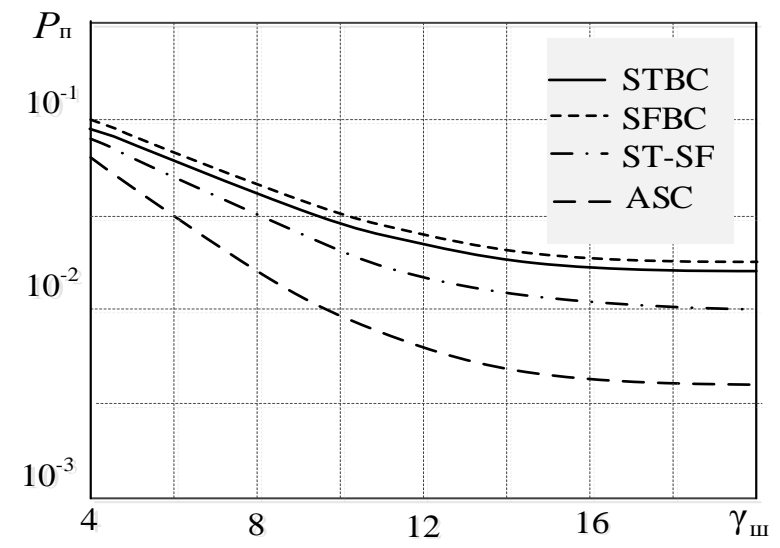

Рисунок 3 - Завадостійкість системи передачі для методів ASC, STBC, SFBC i ST-SF при $f_{\text {д }} T \in[0,01 . .0,2]$ та $\sigma \in\left[6,5 . .13,5 \cdot 10^{-6} \mathrm{c}\right]$, QPSK

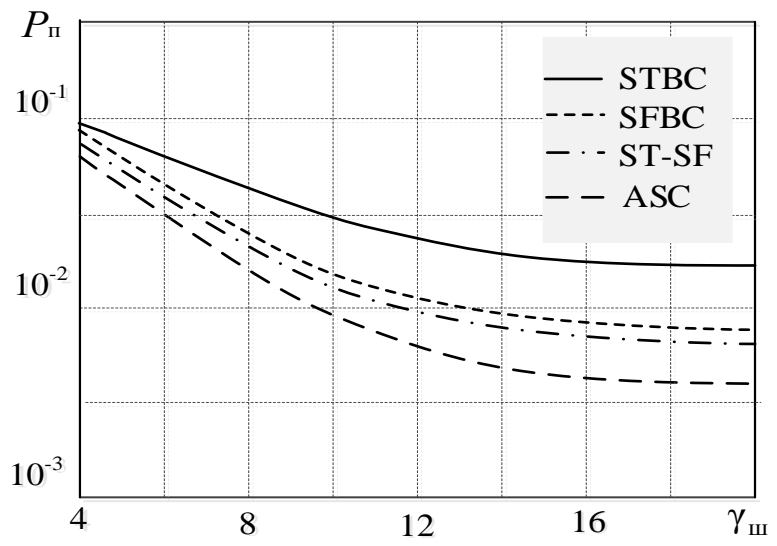

Рисунок 4 - Завадостійкість системи передачі для методів ASC, STBC, SFBC i ST-SF при $f_{\text {д }} T \in[0,1 . .0,2]$ та $\sigma \in\left[0,5 . .13,5 \cdot 10^{-6} \mathrm{c}\right]$, QPSK

Комбінований метод ST-SF також не дає значного покращення завадостійкості системи передачі так, як частина OFDM-символів приймається в умовах одночасно високих рівнів нестаціонарності та частотної селективності, що негативно впливають на ймовірність помилки. Метод ASC в обох випадках $є$ достатньо ефективний (при $P_{\text {п }} \geq 7 \cdot 10^{-3} . .3 \cdot 10^{-2}$ забезпечує енергетичний виграш 2,5 ..4,0 дБ в порівнянні з методом ST-SF).

У каналах з одночасно високими рівнями частотної селективності та нестаціонарності (рис.5) завадостійкість системи передачі в цілому знижується. Однак метод ASC зберігає свою ефективність (при $\gamma_{\text {ш }}>10,5 . .17,9$ дБ забезпечує $P_{\Pi}<3 \cdot 10^{-2} .7 \cdot 10^{-3}$ ).

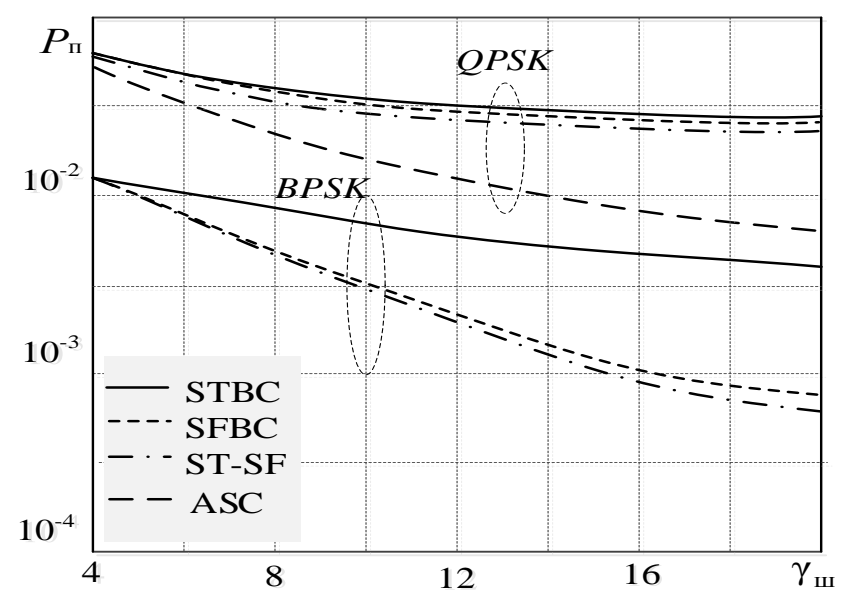

Рисунок 5 - Завадостійкість системи передачі для методів ASC, STBC, SFBC i ST-SF при

$$
f_{\text {д }} T \in[0,1 . .0,2] \text { та } \sigma \in\left[6,5 . .13,5 \cdot 10^{-6} \mathrm{c}\right], \mathrm{QPSK}
$$

У мережах безпроводового зв'язку спеціального призначення під впливом засобів радіоелектронної боротьби шумова захищеність каналу критично знижується. В цих умовах запропонований метод ASC, що використовує BPSK досягає максимальної ефективності за рахунок просторово-частотного кодування $\overline{S F}$. При $\gamma_{\text {ш }}<10$ дБ метод ASC забезпечує ймовірність помилки $P_{\text {п }}<5.7 \cdot 10^{-3}$ з енергетичним виграшем близько 3 дБ і має стрімку тенденцію до зростання в разі покращення шумової захищеності каналу.

Висновки. Реальні канали мереж мобільного зв'язку та широкосмугового доступу є нестаціонарними та частотно-селективними 3 неінваріантними в часі параметрами. Відомі 
базові методи просторового кодування SFBC, STBC та їх удосконалені версії WHSTBC-CC i $\overline{S F} \epsilon$ ефективними лише для окремих областей значень статистичних параметрів нестаціонарності та частотної селективності. Протиріччя між впливом нестаціонарності та частотної селективності на структурно-параметричну оптимізацію технології MIMO-OFDM об’єктивно ускладнює розробку універсального високоефективного методу просторового кодування для широкого класу нестаціонарних частотно-селективних каналів.

Запропонований метод адаптивного просторового кодування ASC в залежності від значень параметрів каналу реалізує оптимальне ситуативне застосування методів SFBC, STBC, WHSTBC-CC, $\overline{S F}$ і забезпечує ефективне використання нестаціонарних частотно-селективних каналів 3 неінваріантними в часі параметрами.

Метод ASC може бути використаний в перспективних технологіях безпроводового зв'язку.

Напрямом подальших досліджень є узгодження методу ASC з методами адаптивної модуляції і завадостійкого кодуванням АМС в рамках єдиної сигнально-кодової конструкції.

\section{СПИСОК ВИКОРИСТАНОЇ ЛІТЕРАТУРИ}

[1] L. Hanzo, J. Akhtman, and L. Wang, MIMO-OFDM for LTE,WiFi, and WiMAX : coherent versus non-coherent and cooperativeturbo-transceivers. United Kingdom: IEEE, 2011.

[2] И.А. Гепко, В.Ф. Олейник, та Ю.Д. Чайка, Современные беспроводные сети: состояние и перспективы развития. Київ, Україна: ЕКМО, 2009.

[3] М.Г. Бакулин, В.Б. Крейнделин, А.М. Шлома, та А.П. Шумов, Технология ОFDM, Москва, Российская Федерация: Горяча линия-Телеком, 2016.

[4] S.A. Nizamaldeen, and T.M. Al-Qaradaghi, "A comparison between STBC-OFDM and SFBCOFDM", International Journal of Arts and Sciences, vol. 6, no. 5, pp. 157-166, 2014.

[5] H.G. Yeh, "Architectures for MIMO-OFDM system in frequency selective mobile fading channels", IEEE Transactions on circuits and systems, vol. 62, no. 12, pp. 1189-1193, 2015. doi: 10.1109/TCSII.2015.2498300.

[6] A. Al-Dweik, S. Muhaidat, and F. Kalbat, "Robust MIMO-OFDM system for frequency selective mobile wireless channels", IEEE transaction on Vehicular Technology, vol. 64, iss. 5, pp. 1-11, 2014. doi: 10.1109/TVT.2014.2340736.

[7] H. Yeh, Y.K. Chang, and B. Hassibi, "A scheme for canceling intercarrier interference through conjugate transmission for multicarrier communication systems", IEEE Trans. Wireless Commun., vol. 6, no. 1, pp. 3-7, 2007.

[8] М.І.Науменко, та Л.М. Погребняк, "Удосконалений метод просторово-часового блочного кодування для частотно-селективних нестаціонарних каналів систем військового радіозв’язку”, Збірник наукових пращь ВITI, № 1, с. 81-86, 2017.

[9] N. Lee, and J. Kang, "Adaptive switching between space-time and space-frequency block coded OFDM Systems”, in Proc. IEEE Military Communications Conference, San Diego, pp. 7-13, 2008. doi: 10.1109/MILCOM.2008.4753221.

[10] A. Omri, R. Hamila, A. Hazmi, R. Bouallegue, and A. Al-Dweik, "Enhanced Alamouti decoding scheme for DVB-T2 systems in SFN channels", in Proc. IEEE 22nd International Symposium on Personal, Indoor and Mobile Radio Communications, Toronto, pp. 2046-2050, 2011. doi: 10.1109/PIMRC.2011.6139779.

[11] A. Youssefi, N. Bounouader, Z. Guennoun, and J. El. "Adaptive Switching between Space-Time and Space-Frequency Block Coded OFDM Systems in Rayleigh Fading Channel”, International Journal of Communications, Network and System Sciences, no. 6., pp. 316 - 323, 2013. doi: 10.4236/ijens.2013.66034.

[12] Б. Скляр, Цифровая связь. Теоретические основы и практическое применение, Москва, Российская Федерация: Издательский дом «Вильямс», 2003.

Стаття надійшла до редакції 06 вересня 2017 року. 


\section{REFERENCE}

[1] L. Hanzo, Jos. Akhtman, and Li Wang, MIMO-OFDM for LTE, WiFi, and WiMAX : coherent versus non-coherent and cooperativeturbo-transceivers. United Kingdom: IEEE, 2011.

[2] Y.A. Hepko, V.F. Oleinyk, and Y.D. Chaika, The modern wireless networks: status and perspectives of development, Kyiv, Ukraine: "EKMO", 2009.

[3] M.G. Bakulin, V.B. Kreindelin, A.M. Shola, and A.P. Shumov, Technology OFDM. Moskow, Russia: Hot Line-Telecom, 2016.

[4] S.A. Nizamaldeen, and T.M. Al-Qaradaghi, "A comparison between STBC-OFDM and SFBCOFDM", International Journal of Arts and Sciences, vol. 6, no. 5, pp. 157-166, 2014.

[5] H.G. Yeh, "Architectures for MIMO-OFDM system in frequency selective mobile fading channels", IEEE Transactions on circuits and systems, vol. 62, no. 12, pp. 1189-1193, 2015. doi: 10.1109/TCSII.2015.2498300.

[6] A. Al-Dweik, S. Muhaidat, and F. Kalbat, "Robust MIMO-OFDM system for frequency selective mobile wireless channels", IEEE transaction on Vehicular Technology, vol. 64, iss. 5, pp. 1-11, 2014. doi: 10.1109/TVT.2014.2340736.

[7] H. Yeh, Y.K. Chang, and B. Hassibi, "A scheme for canceling intercarrier interference through conjugate transmission for multicarrier communication systems", IEEE Trans. Wireless Commun., vol. 6, no. 1, pp. 3-7, 2007.

[8] M.I. Naumenko, and L.M. Pohrebniak, "Advanced method of space-time block coding frequency selective time-varying channels of systems of a military radio communication", Collection of research papers VITI, no. 1, pp. 81-86, 2017.

[9] N. Lee, and J. Kang, "Adaptive switching between space-time and space-frequency block coded OFDM Systems”, in Proc. IEEE Military Communications Conference, San Diego, pp. 7-13, 2008. doi: 10.1109/MILCOM.2008.4753221.

[10] A. Omri, R. Hamila, A. Hazmi, R. Bouallegue, and A. Al-Dweik, "Enhanced Alamouti decoding scheme for DVB-T2 systems in SFN channels", in Proc. IEEE 22nd International Symposium on Personal, Indoor and Mobile Radio Communications, Toronto, pp. 2046-2050, 2011. doi: 10.1109/PIMRC.2011.6139779.

[11] A. Youssefi, N. Bounouader, Z. Guennoun, and J. El. "Adaptive Switching between Space-Time and Space-Frequency Block Coded OFDM Systems in Rayleigh Fading Channel", International Journal of Communications, Network and System Sciences, no. 6., pp. 316 - 323, 2013. doi: 10.4236/ijens.2013.66034.

[12] B. Skliar, Digital communication. Theoretical bases and practical application. Moskow, Russia: Publishing house "Vyliams", 2003.

ЛЮДМИЛА ПОГРЕБНЯК, НИКОЛАЙ НАУМЕНКО

\section{МЕТОД АДАПТИВНОГО ПРОСТРАНСТВЕННОГО КОДИРОВАНИЯ СИГНАЛА ДЛЯ НЕСТАЦИОНАРНЫХ ЧАСТОТНО-СЕЛЕКТИВНЫХ КАНАЛОВ БЕСПРОВОДНОЙ СВЯЗИ}

Рассмотрено совместное применение ортогонально-частотного мультиплексирования (OFDM) и системы многоэлементных антенн (MIMO) в беспроводных нестационарных частотно-селективных каналах сетей мобильной связи и сетей широкополосного доступа. Проведен анализ методов пространственного блочного кодирования (пространственновременного (STBC), пространственно-частотного (SFBC), пространственно- временного с повышенной устойчивостью к нестационарности (WHSTBC-CC) и пространственночастотного с повышенной устойчивостью к частотной селективности $(\overline{S F}))$ и определены условия их эффективного использования. Показано, что методы пространственного блочного кодирования эффективны только для отдельных диапазонов значений статистических параметров нестационарности и частотной селективности (нормированного доплеровского 
сдвига частоты и среднеквадратичной задержки распространения сигналов). Противоречия влияния временной и частотной селективности на структурно-параметрическую оптимизацию технологии MIMO-OFDM объективно затрудняет разработку универсального высокоэффективного метода пространственного кодирования для широкого класса нестационарных частотно-селективных каналов. С целью увеличения скорости передачи информации и повышения качества обслуживания пользователей (уменьшение вероятности ошибки передачи информации) предложен усовершенствованный метод адаптивного пространственного кодирования сигналов. Сущность усовершенствования заключается в комплексном учете шумовой защищенности канала (отношение сигнал / шум), нормированного значения доплеровского сдвига частот, коэффициентов временной и частотной корреляции при определении оптимального ситуативного применения SFBC,

$\mathrm{STBC}$, WHSTBC-CC, $\overline{S F}$, что позволяет обеспечить эффективное использование нестационарных частотно-селективных каналов с неинвариантными во времени параметрами.Полученные научные результаты могут быть использованы при модернизации существующих и проектировании перспективных сетей беспроводной связи.

Ключевые слова: нестационарность, частотная селективность, MIMO, OFDM, методы пространственного кодирования, сеть мобильной связи, сеть широкополосного доступа.

\section{LIUDMYLA POHREBNIAK, MYKOLA NAUMENKO}

\section{METHOD OF ADAPTIVE SPATIAL CODING OF SIGNALS FOR NON-STATIONARY FREQUENCY-SELECTIVE CHANNELS OF WIRELESS COMMUNICATION}

General using of orthogonal-frequency multiplexing (OFDM) and multi-element antenna systems (MIMO) in wireless non-stationary frequency selective channels of mobile networks and broadband networks were considered. Methods of spatial block encoding (space-time (STBC), spatial-frequency (SFBC), spatial-frequency with high resistance to non-stationary (WHSTBC-CC) and spatial-frequency with increased resistance to frequency selectivity $(\overline{S F})$ ) were analyzed and conditions for their efficient use were determined. It was shown that methods of spatial block coding are effective only for certain diapason of the values of statistical parameters of non-stationary and frequency selectivity (normalized Doppler frequency shift and mean square delay of signal propagation). The contradiction of the time influence and frequency selectivity on structuralparametric optimization of the technology MIMO-OFDM complicates objectively the development of the universal high-performance spatial encoding method for a wide class of non-stationary frequency-selective channels. The advanced method of adaptive spatial signal coding was proposed in order to increase the speed of the information transfer and quality of users service (reducing the probability of the information transmission error). The essence of the improvement is to integrate the channel noise protection of the channel (signal to noise ratio), normalize the value of the Doppler frequency shift, time and frequency correlation coefficients when determining the optimal situational application of SFBC, STBC, WHSTBC-CC, $\overline{S F}$, that ensure the proper use of non-stationary frequency-selective channels with non-invariant parameters in time. The obtained scientific results can be used for modernization of existing and designing perspective wireless networks.

Keywords: non-stationary, frequency-selectivity, MIMO, OFDM, spatial coding methods, mobile communication network, broadband access network.

Людмила Михайлівна Погребняк, ад’юнкт, Військовий інститут телекомунікацій та інформатизації,Київ, Україна.

E-mail: Pogrebnaklm@gmail.com.

Микола Іванович Науменко, доктор технічних наук, професор, професор кафедри транспортних мереж, Військовий інститут телекомунікацій та інформатизації, Київ, Україна.

E-mail: Naumenko@gmail.com. 
Людмила Михайловна Погребняк, адъюнкт, Военный институт телекоммуникаций и информатизации, Киев, Украина.

Николай Иванович Науменко, доктор технических наук, профессор, профессор кафедры транспортных сетей, Военный институт телекоммуникаций и информатизации, Киев, Украина.

Liudmyla Pohrebniak, postgraduate student, Military institute of telecommunications and informatization, Kyiv, Ukraine.

Mykola Naumenko, doctor of technical sciences, professor, professor at the transport networks academic department, Military institute of telecommunications and informatization, Kyiv, Ukraine.

\author{
УДК 621.396 \\ РУСЛАН АБДУРАМАНОВ \\ ЮРИЙ ХЛАПОНИН \\ АНТОН ХАДДАД
}

\title{
ПРИМЕНЕНИЕ МЕТОДОВ РЕГРЕССИОННОГО АНАЛИЗА ДЛЯ МОНИТОРИНГА И УПРАВЛЕНИЯ ТЕЛЕКОММУНИКАЦИОННЫМИ СИСТЕМАМИ
}

Телекоммуникационные системы являются важнейшей частью современной жизни человека. Абсолютно все аспекты деятельности современного человека попали в зависимость от эффективной работы телекоммуникационных сетей. Развитие телекоммуникационных систем и компьютерных сетей обуславливает необходимость создания и надежного функционирования большого набора инфокоммуникационных сервисов, обеспечивающих эффективную работу пользователя с разнородной информацией в телекоммуникационной сети. Исторически сложившаяся неоднородность, как телекоммуникационных систем, компьютерных сетей, сетевых информационных ресурсов, так и аудитории пользователей, которой данная информация адресована, осложняет объективный анализ и мониторинг телекоммуникационных архитектур и ресурсов. Поэтому, безусловно, актуально, что при эксплуатации телекоммуникационных систем и компьютерных сетей должен быть использован, достаточно широкий спектр современных и научно обоснованных технических и технологических решений их анализа и мониторинга. Этот факт и обуславливает важность решения задач мониторинга и управления телекоммуникационными системами. В последнее время стали популярными интеллектуальные системы принятия решений на базе систем обработки данных с применением технологий машинного обучения. В данной работе рассматривается одна из таких технологий, основанная на применении логистической регрессии. Используя данные, характеризующие работу телекоммуникационной сети, была построена модель, описывающая работу сети. В частности, доказана возможность использования логистической регрессии для прогноза вероятности возникновения неэффективной работы сетей на базе процессов, которые в них протекают. На базе модели, была построена интеллектуальная система принятия решения для мониторинга и управления состоянием работы сети в реальном времени.

Ключевые слова: телекоммуникационная система, интеллектуальная система принятия решений, логистическая регрессия, компьютерная сеть, протокол SNMP.

Постановка проблемы. Современный мир сложно представить без многочисленных сложных цифровых радиоэлектронных технических устройств, которые не только помогают

(C) Р. Абдураманов, Ю. Хлапонин, А. Хаддад, 2017 